\title{
Effect of Modified AA5356 Filler on Corrosion Behavior of AA6061 Alloy GTA Welds
}

\author{
${ }^{1}$ N. Ramanaiah ${ }^{2}$ B. Balakrishna, ${ }^{3}$ K. Prasad Rao \\ ${ }^{1}$ Professor Dept. of Metallurgical and materials Engineering, IITM, Chennai. \\ ${ }^{2}$ Associate Professor, Dept. of Mechanical Engineering, JNTU (K), Kakinada \\ ${ }^{3}$ Associate Professor, Dept. of Mechanical Engineering, AUCE, Visakhapatnam,
}

\begin{abstract}
The corrosion behavior of the fusion zone of gas tungsten arc (GTA) welds of AA6061 alloy was studied. Role of gas tungsten arc welding techniques such as continuous current (CC) and pulsed current (PC) and reference filler (AA5356) were studied. Role of different grain refiners such as scandium, zirconium and Tibor in the reference filler was studied. Dynamic polarization testing was used to determine the pitting corrosion resistance of the fusion zone. Optical studies was carried out to find the mechanism of corrosion. The fusion zone of welds made with the $0.5 \%$ Sc with AA5356 filler with PC technique shown better corrosion resistance.
\end{abstract}

\section{Introduction}

Gas tungsten arc welding (GTAW) process is widely used for joining aluminium alloys for various applications in the aerospace, defence and automotive industries. Fusion welding leads to physical, chemical and metallurgical changes in aluminium alloys ${ }^{1}$. One of the reasons for the chemical changes in the fusion zone of welds is due to the different chemical compositions of the filler materials used. The resistance to corrosion of aluminum alloy welds is affected by the alloy being welded, the filler alloy and the technique used. When localised corrosion does occur in aluminium welds, it may take the form of preferential attack of the weld bead, pitting, intergranular attack or exfoliation may occur in a heat affected zone (HAZ) a short distance from the weld bead. Welds in $\mathrm{Al}-\mathrm{Mg}-\mathrm{Si}$ alloys (AA6061) generally have a good resistance to atmospheric corrosion, but in specifically corrosive environments such as seawater localised corrosion may occur. Selection of proper filler wire is important to avoid cracking during welding and to optimize corrosion resistance. When the solution potential of the filler is the same as that of the base metal, optimum corrosion resistance is obtained. In some cases, an intermetallic phase formed by the base metal and filler wire determines the final corrosion resistance of the weld.

In general, the welding procedure that has the lowest influence on the microstructure has the least chance of reducing the corrosion resistance of aluminum weldments. Though literature on the corrosion behavior of aluminium alloys is available, the same cannot be said of their welded counterparts in view of the chemical and microstructural changes caused by welding.

Gas tungsten arc welding (GTAW) is widely applied method to join aluminum alloys and detailed studies on the effect of alternate current pulsing technique on the Corrosion behavior of heat treatable aluminum alloys are not fully available in the literature. The present investigation Corrosion behavior of AA6061 gas tungsten arc welds is studied. It was intended to study the effects of different current modes, viz., such continuous current (CC) and pulsed current (PC) and application of AA5356 filler containing different grain refiners such as scandium, zirconium and Tibor.

\section{Experimental details}

The investigations were carried out on AA6061 (6 mm thick) alloy in T6 temper. Base metal-T6 was solution treated (at $530^{\circ} \mathrm{C}$ for $1 \mathrm{~h}$ ) and artificially aged (at $160^{\circ} \mathrm{C}$ for $18 \mathrm{~h}$ ). The composition of the base alloy and AA5356 filler wire is given in Table 1.The alternate current (AC) GTAW process was used. Autogenous, bead-on-plate, full penetration welds were produced. The weld bead was made perpendicular to the sheet rolling direction. Prior to welding, the base material coupons, reference fillers and grain refiners were wire brushed and thoroughly cleaned with acetone. Weighed filler material and grain refiner master alloy strips ( $\mathrm{Al}-\mathrm{Sc}, \mathrm{Al}-\mathrm{Zr}$ and $\mathrm{Al}-\mathrm{Tibor}$ ) of uniform cross section were press fitted into a rectangular groove machined in the base plate and tack welded. Details of the welding parameters are presented in Tables 2 and 3. The chemical compositions of fusion zone deposited with AA5356 fillers is shown in Table 4.The scandium content of the fusion zones was varied by varying the size of the groove in the base metal and size of the filler strip. The chemical compositions of fusion zone deposited with AA5356 fillers containing grain refiners is shown in Table 4.Two types of current modes were used: CC and PC. Optimum welding parameters based on previous work ${ }^{2}$ were used. Specific details of CC GTAW and PC GTAW are given in Table 2 and 3.

Table 1

Chemical Composition of the base metal and filler

\begin{tabular}{lcccccc}
\hline Material & $\mathrm{Mg}$ & $\mathrm{Si}$ & $\mathrm{Fe}$ & $\mathrm{Mn}$ & $\mathrm{Cu}$ & $\mathrm{Al}$ \\
\hline AA6061 -base metal & 0.96 & 0.73 & 0.24 & 0.33 & 0.23 & Balance \\
AA5356-filler & 5.00 & 0.27 & 0.40 & 0.10 & 0.10 & Balance \\
\hline
\end{tabular}


Table 2

Welding parameters used for CC welding

\begin{tabular}{ll}
\hline Welding parameter & Selection \\
\hline Current & $66 \mathrm{~A}$ \\
Speed & $3.5 \mathrm{~mm} / \mathrm{s}$ \\
Voltage & $12-15 \mathrm{~V}$ \\
Electrode & Thoriated W, $2 \mathrm{~mm}$ dia \\
Shielding gas & Argon \\
\hline
\end{tabular}

Table 3

Welding parameters used for PC welding

\begin{tabular}{ll}
\hline Welding parameter & Selection \\
\hline Peak current $\left(I_{\mathrm{p}}\right)$ & $88 \mathrm{~A}$ \\
Background current $\left(I_{\mathrm{b}}\right)$ & $44 \mathrm{~A}$ \\
Speed & $3.5 \mathrm{~mm} / \mathrm{s}$ \\
Voltage & $12-15 \mathrm{~V}$ \\
Pulse frequency & $6 \mathrm{~Hz}$ \\
Pulse on-time & $50 \%$ of cycle time \\
Electrode & Thoriated W, $2 \mathrm{~mm}$ dia \\
Shielding gas & Argon \\
\hline
\end{tabular}

Actual composition of fusion zones is given in Table 4. The samples of welds from the fusion zone region were polished on Emery papers and disc cloth to remove the very fine scratches. Polished surfaces were etched with Keller's reagent. The microstructures were recorded with an image analyzer attached to the metallurgical microscope. A software based PAR Basic electrochemical system was used for conducting corrosion testing of the fusion zone. Potentiodynamic polarisation testing was used to determine the pitting corrosion resistance.

Saturated calomel electrode (SCE) and carbon electrode were used as reference and auxiliary electrodes respectively. All the experiments were conducted in $3.5 \% \mathrm{NaCl}$ solutions with the $\mathrm{pH}$ adjusted to 10 . The potential scan was carried out at $0.166 \mathrm{mV} \mathrm{s}-1$ with an initial potential of $20.25 \mathrm{~V}$ (OC, open circuit) SCE to the final potential of pitting. The exposure area for these experiments was $1 \mathrm{~cm}^{2}$. The potential at which the current increases drastically is treated as critical pitting potential (Epit). Specimens exhibiting more positive potential were considered as those with better pitting corrosion resistance.

Table 4

Chemical Composition (Wt \%) of the fusion zone with AA5356 and grain refiners to fusion zone through AA5356

\begin{tabular}{|c|c|c|c|c|c|c|c|c|c|c|}
\hline Material & $\mathrm{Mg}$ & $\mathrm{Si}$ & $\mathrm{Fe}$ & $\mathrm{Mn}$ & $\mathrm{Cu}$ & Sc & $\mathrm{Ti}$ & $\mathrm{Zr}$ & $\mathrm{Al}$ & \\
\hline AA5356-filler & & 2.83 & 0.26 & 0.20 & 0.13 & 0.15 & - & - & - & Bal \\
\hline AA $5356+0.25 \% \mathrm{Sc}$ & & 2.75 & 0.27 & 0.20 & 0.10 & 0.12 & 0.24 & - & - & $\mathrm{Bal}$ \\
\hline AA $5356+0.50 \% \mathrm{Sc}$ & & 2.70 & 0.26 & 0.20 & 0.19 & 0.11 & 0.48 & - & - & Bal \\
\hline AA $5356+Z r$ & & & & 0.26 & 0.21 & 0.12 & - & - & 0.14 & Bal \\
\hline AA5356+Tibor & 2.77 & & 0.25 & 0.20 & 0.12 & - & 0.15 & - & Bal & \\
\hline
\end{tabular}

\subsection{Microstructures}

\section{Results and discussion}

Micrograph of the base metal is shown in the Fig. 1a. It shows number of $\mathrm{Mg} 2 \mathrm{Si}$ particles present in artificially aged (T6) alloy. The microstructure was columnar (Fig. 1b) without grain refiners and significant grain refinement was noticed when grain refiners were added to the fusion zone (Fig. 1c). 


\subsection{Effect of grain refiners}

Pitting potentials of fusion zone deposited with AA5356 filler with grain refiners are shown in Table 5. For comparative purposes, pitting potentials of base metal and fusion zone obtained without grain refiners also shown in Table 5 .

It can be seen from the results that filler metal composition and welding technique have strong influence on the pitting potentials of fusion zone of AA6061 alloy. The pitting potentials of fusion zone of this alloy is found to be in the range of $-690--580 \mathrm{mV}$ depending on the filler composition and process technique.

Fusion zone with AA5356 without grain refiners showed the least pitting potential. As for technique, CC welds showed greater pitting corrosion susceptibility than PC welds. The pitting corrosion susceptibility was found to decrease with additions of grain refiners to fusion zone through AA5356 filler metal. Among the grain refiners studied filler metal with $0.5 \% \mathrm{Sc}$ was observed to provide the highest pitting corrosion resistance followed by Tibor.

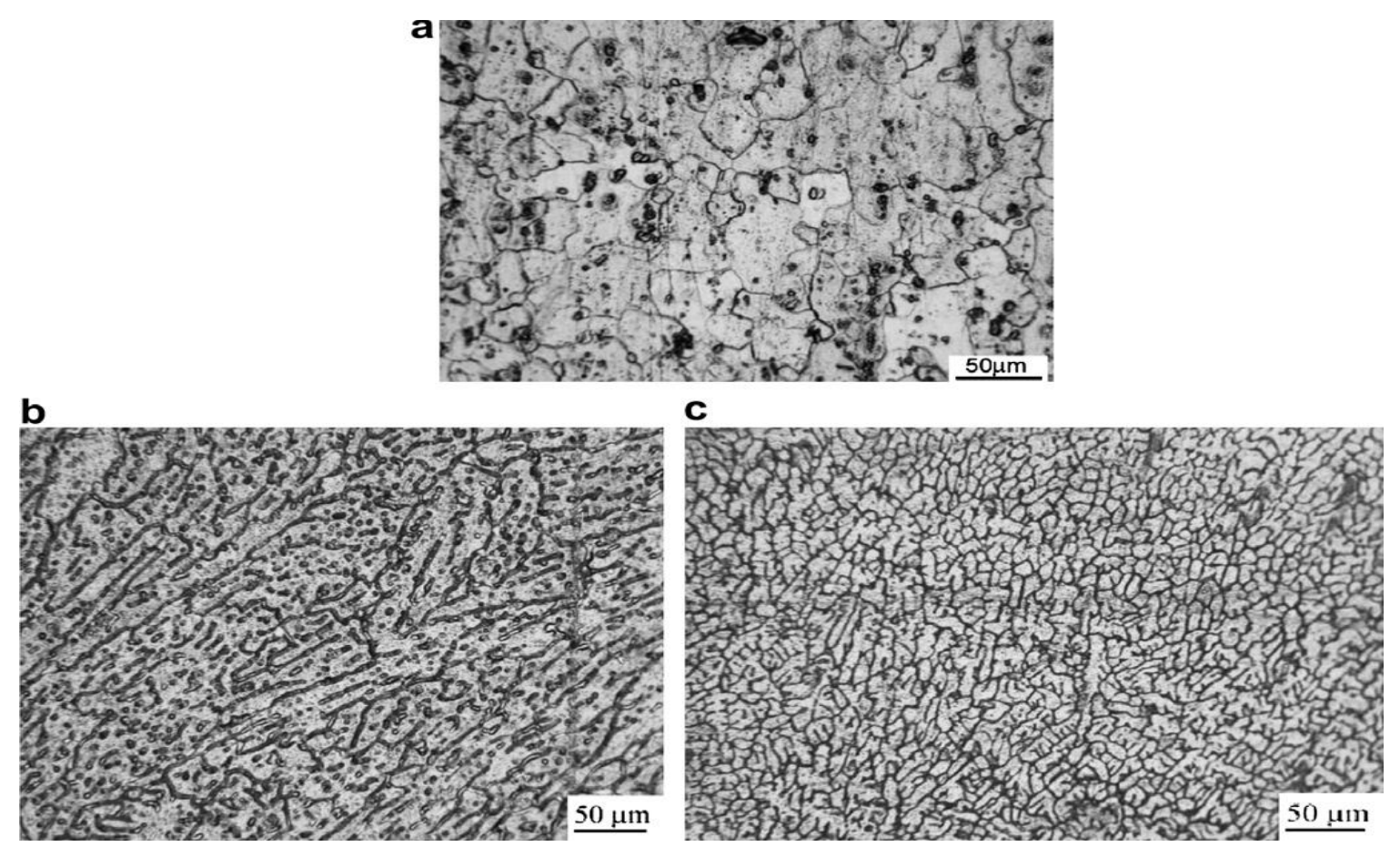

Fig. 1. Micrographs of (a) Base Metal-T6 and (b) Fusion Zone AA5356 CC

(C) Fusion Zone AA5356+05\%Sc, PC

Table 5

Pitting potentials of fusion zone with AA5356 filler and grain refiners to fusion zone through AA5356

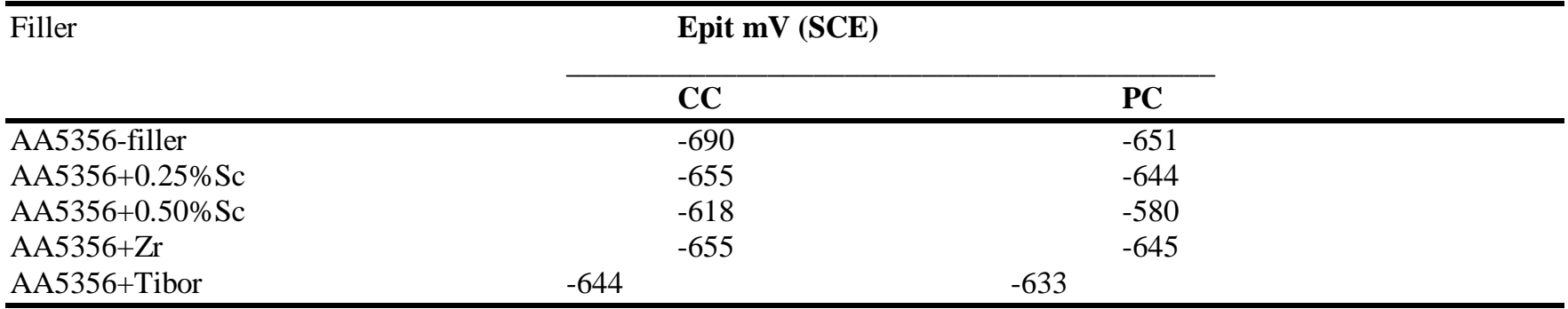

These results can be discussed in the light of their micro structural aspects. Welds made with AA5356 filler (without grain refiners, with CC) showed larger size of pits and pit density (Fig. 2a and b) Than PC indicating poor pitting corrosion resistance. Significant reduction in the size of pits and number of pits was observed with $0.5 \% \mathrm{Sc}$ addition to AA5356filler. It showed reduction in pitting density and number of pits among the filler metals studied (Fig. 3c). Pit size was also reduced with Tibor, $\mathrm{Zr}$ addition (Fig. 3 d-e). Pit density was less with Tibor when compared to $\mathrm{Zr}$ addition. Out of all the grain refiners studied $0.5 \% \mathrm{Sc}$, PC resulted lowest pit density. These results indicate that fusion zone composition has got a significant effect on pitting corrosion resistance of AA6061. Ganiev ET al ${ }^{3}$, compared corrosion potential of pure aluminum to that of Sc addition to pure aluminum. Vyazovikina ${ }^{4}$ proposed that corrosion potential improvement in in $\mathrm{Al}-\mathrm{Zn}$ alloys are due to the presence of $\mathrm{Al}_{3} \mathrm{Sc}$ particles and Sinyavskii et al ${ }^{5}$ reported that the presence of $\mathrm{Al}_{3} \mathrm{Sc}$ improved the corrosion potential of $\mathrm{Al}-\mathrm{Zn} \sim \mathrm{Mg}-\mathrm{Cu}$ alloys. It seems that the genera trend is that addition of Sc to Aluminum alloy makes it slightly more noble. 

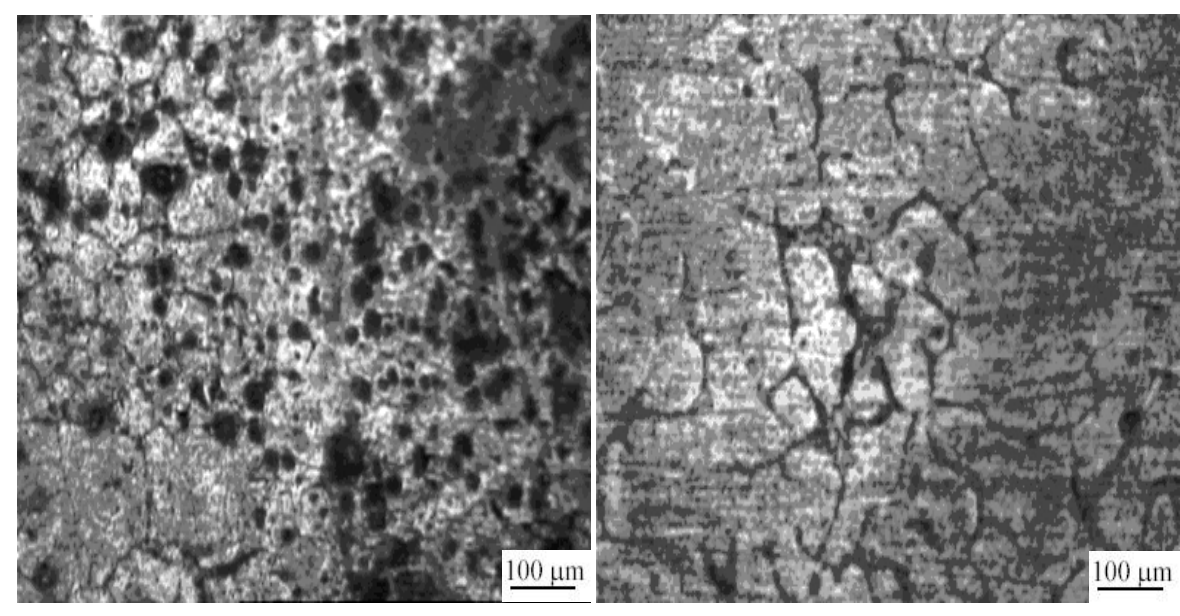

Fig. 2 Optical micrographs of fusion zone after corrosion test

(a) AA5356 CC (b) AA5356PC

\subsection{Effect of welding technique}

High thermal gradients, characteristic of conventional continuous current $(\mathrm{CCW})$, the segregation of elements and liquid film formation at the grain boundaries of gas tungsten arc welding (CCTIG) limits the use of base metal properties such as strength and corrosion resistance. ${ }^{6}$

In case of PC GTA welding, cycling of the welding current from a high level to a low level at a selected regular frequency. The high level or the peak current is generally selected to give adequate penetration and bead contour, while the low level or the background current is set at a level sufficient to maintain a stable arc. This permits arc energy to be used efficiently to fuse a spot of controlled dimensions in a short time producing the weld as a series of overlapping nuggets and limits the wastage of heat by conduction into the adjacent parent material in normal constant current welding. Metallurgical advantages of PC welding frequently reported in the literature include refinement of fusion zone grain size and substructure, reduced width of HAZ, control of segregation, etc. All these factors help in improving weld mechanical properties. The enhanced fluid motion in the weld pool homogenizes the weld metal composition and helps in reducing the segregation and porosity. Therefore the improved pitting and general corrosion resistance of the fusion zone of the PC GTA AA6061 welds compared to that of CC GTA welds, was attributed to the reduced segregation and refining of the eutectics of the fusion zone.

\section{Conclusions}

1. Pitting corrosion resistance of AA6061 alloy was relatively less when pulsed current GTA welding was adopted compared to continuous current.

2. Pitting corrosion resistance of AA6061 alloy was relatively less when filler materials contained grain refiners such as scandium, $\mathrm{Zr}$ or Tibor. The highest Pitting corrosion resistance was found with $0.5 \% \mathrm{Sc}$ containing AA5356 filler material.

3. Highest Pitting corrosion resistance in AA6061 alloy welds was noticed when AA5356 filler containing $0.5 \%$ Sc was used with pulsed arc GTA welding.

\section{References}

1. Davis, J. R.: 'Corrosion of aluminium alloys', 2nd ed., 2000, Metals Park, OH, ASM International.

2. Prasad Rao, K., Ramanaiah, N., Viswanathan, N., 2008, Mat. Das. 29, 179-186.

3. Ganiev, I. N., 1995, Prot. Met, 31, 543-546.

4. Vyazovikina, N. V., 1999, Prot. Met, 35, 448-453.

5. Sinayaskii,V. S., V.D. Valkov and E. Titkova, 1998, Prot.Met., 34, 549-555.

6. S. Kou: 'Welding metallurgy', 2nd edn.; 2003, NY, Wiley. 


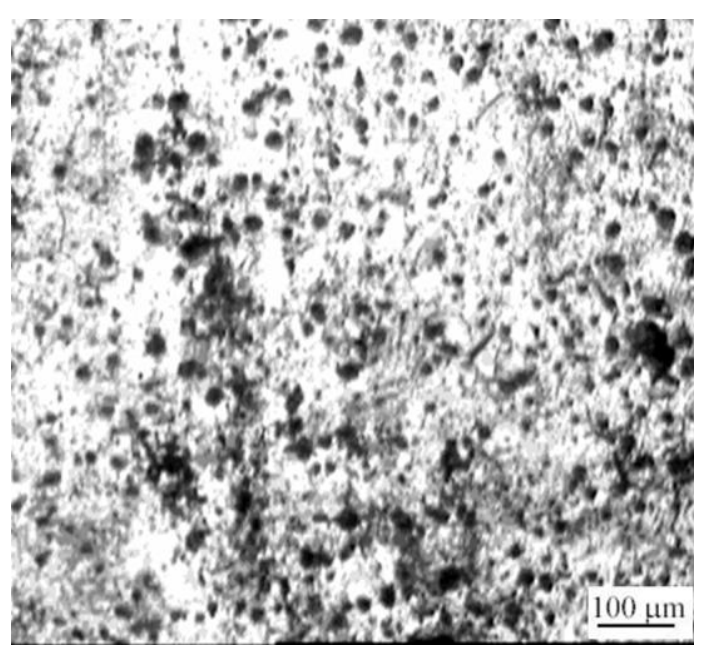

(a)

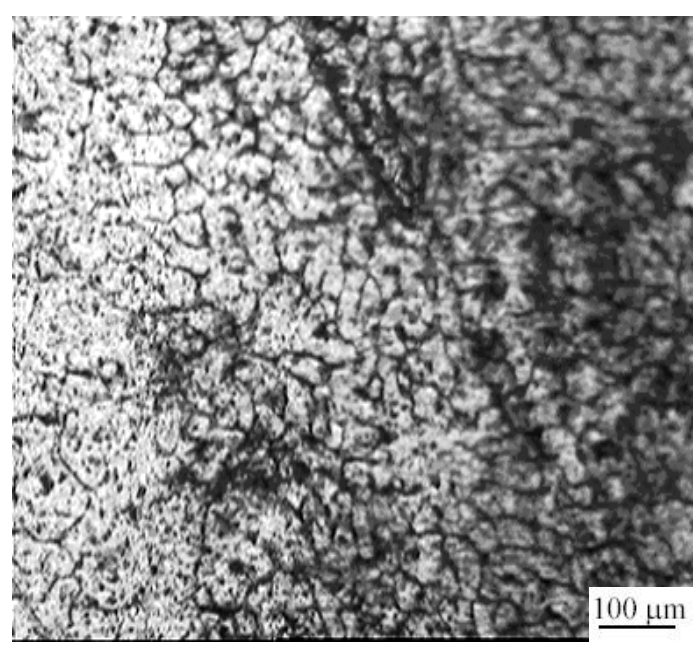

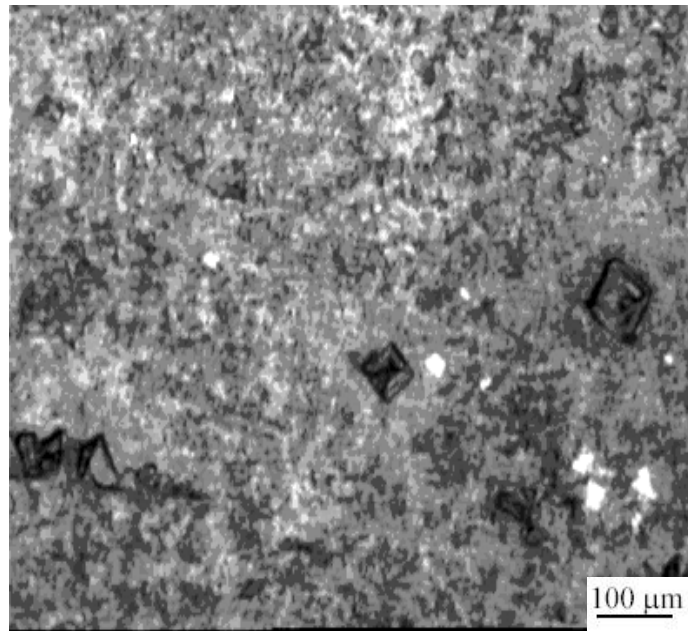

(b)

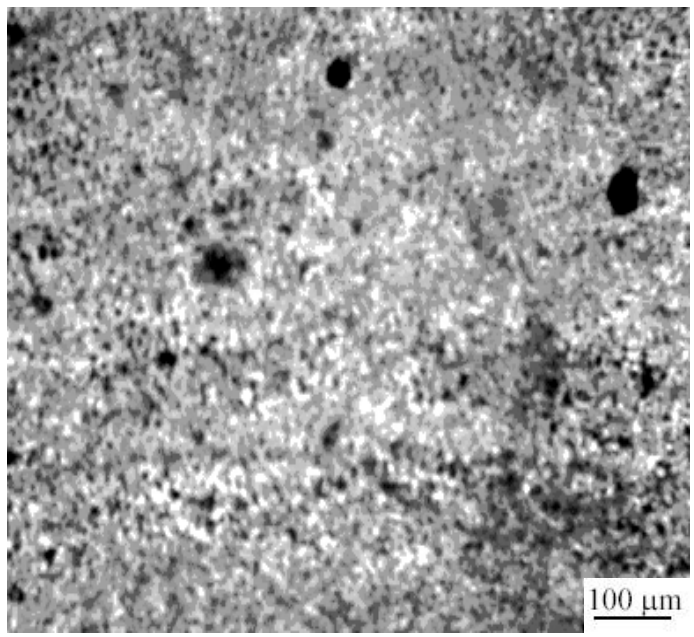

(d)

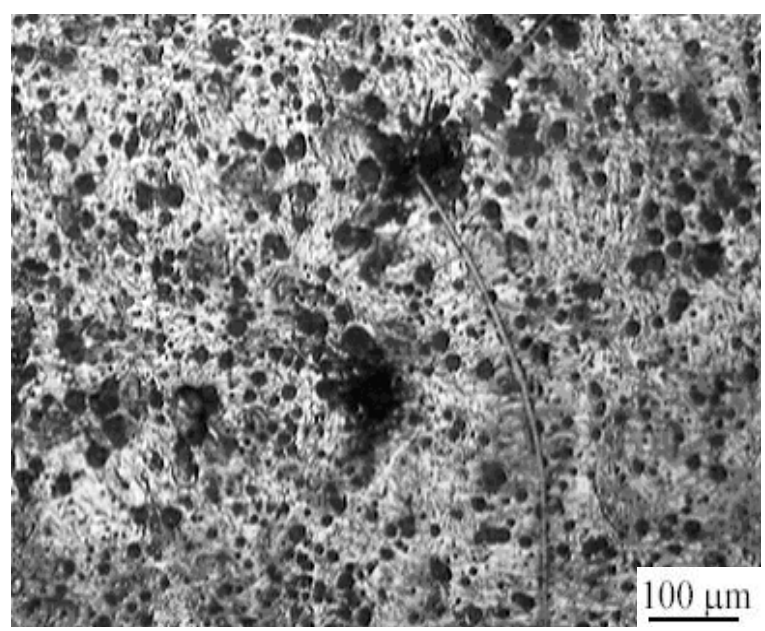

